\title{
Engineering Aspect of Modern Concept of Professional Education of Artists and Designers in Academic Figure
}

\author{
Elena Vasilenko*1, Pavel Vasilenko², Natalya Saenko ${ }^{3}$, Viacheslav Borysov ${ }^{4}$, Svitlana Borysova $^{5}$, Iryna Prodan ${ }^{6}$ \\ ${ }^{1,2}$ K. G. Razumovsky Moscow State University of technologies and management (the First Cossack University) (RAZUMOVSKY \\ MSUTM (FCU)), 109004, st. Ground Val, 73, Moscow, Russia. \\ ${ }^{3}$ Moscow Polytechnic University, Moscow, Russia. \\ ${ }^{4}$ Khortytsia National Educational Rehabilitation Academy, Ukraine. \\ ${ }^{5}$ Donbas State Pedagogical University, Ukraine. \\ ${ }^{6}$ Luhansk Taras Shevchenko National University, Ukraine.
}

\begin{abstract}
The article studies the pedagogical process of vocational education in the field of academic drawing. The pedagogical problem of the connection of theory and practice. The need for a modern approach to the pedagogical process in the training of artists and designers, consistency with the curriculum and work programs of the disciplines. The entire volume of theoretical knowledge combined with practical knowledge in the most generated format enables the student to successfully master the basics of visual literacy. After analyzing the final certification and evaluation of students, it can be noted that the necessary theoretical information is not fully received. The main task in the development of academic drawing in higher education is an in-depth study of the lecture material and the application of visual literacy in practice. A modern conceptual approach to solving pedagogical problems of forming professional competencies at a high level in the subject "Academic drawing" is one of the topical problems of modern education in the field of fine arts and design.
\end{abstract}

Keywords: artist, designer, academic drawing, visual literacy Introduction, theoretical information

\section{INTRODUCTION}

The basis of academic drawing is theory and practice. These are two equivalent components of this process. The task of the pedagogical process in the formation of professional skills and abilities in the academic drawing of students is to confirm theoretical knowledge in practice. The desire of students to achieve goals and work out all aspects of theory in practice makes it possible to successfully master the discipline. The task of a teacher is to ensure that theory and practice complement each other and go in parallel throughout the entire pedagogical process. A famous teacher in the field of academic drawing, such as P. P. Chistyakov, said that everything is based on accurate scientific calculations, on knowledge of laws, and not only on creative freedom. Real art is based on scientific data and cannot exist without it. The role of science, in its highest manifestation, is art. The basis for the acquisition of professional competencies occurs only when the training process is properly organized $[4 ; 12 ; 15 ; 22 ; 23]$.

Professional competencies acquired by students are laid down and developed to the necessary extent [2]. Academic drawing and painting are based on the method of realistic threedimensional representation of the form in space. As well as academic drawing is the basis of all types of fine art [27]. The purpose of studying this discipline is to create conditions for the successful completion of creative tasks. From the first days of academic drawing training, it is necessary to apply various forms of educational work - long-term, constructive, shortterm drawing, as well as a sketch. The active development of a student's compositional thinking depends on the study of academic drawing. Significant in the pedagogical process of academic drawing is the study of plasticity, imagery and artistic and expressive means of performance. All these components make up a single and unbroken system of the discipline "Academic drawing", which is the basis for further development of other professional disciplines.

The international study was carried out jointly by experts from K.G. Razumovsky Moscow State University of technologies (Russia), Moscow Polytechnic University management (Russia) and Lugansk National Taras Shevchenko University (Ukraine), Khortytska National Academy (Ukraine) and Donbas State Pedagogical University (Ukraine).

\section{METHODS}

In the pedagogical process of mastering the "Academic drawing", certain pedagogical conditions and methods can be identified, which are the main ones for the qualitative process of studying a professional discipline:

(1) Methodical distribution in training, which will 
contribute to the successful development of skills in the visual arts, stages of assimilation and study of the theory of the laws of proportions and forms in the study of drawing.

(2) Building the learning process taking into account the development of perspective knowledge, stylistic techniques and compositional solutions.

(3) A Specialized program of tasks and exercises for better development of the discipline and the formation of professional abilities.

(4) Creating creative tension in the educational process.

(5) Conditions of mutual understanding and respect friendly environment.

(6) Monitoring the process of studying academic drawing through regular diagnostic review of works and interpretation of the results obtained.

\section{LITERATURE REVIEW}

In his manuscript, S. P. Roshchin defines the importance of two components of the pedagogical process in the field of academic drawing - theory and practice, saying that they are the basis for the formation and development of professional competencies of students. A certain pedagogical model is built in the following areas: basic ideas about form, perspective, space, tone, General information about style, trends in the history of art and culture, as well as the study of professional methods of teaching and training artists and designers, figurative study of the surrounding world and nature $[1 ; 21]$.

The systematized educational process is based on didactic principles and integration of methodological aspects of the development of students ' compositional thinking [13]. The need for a deeper, modern approach to the pedagogical process of teaching academic drawing, the creation of an effective concept should be based on the development of theory and practice $[10 ; 11]$. The created pedagogical conditions will allow students to reach a qualitatively higher level of mastering the professional discipline and develop the ability to ideologicallycreative research in the future professional activity of a designer $[16 ; 17]$.

The low level of formation of compositional and creative thinking and professional skills in academic drawing can often be seen in the final review of creative and educational practical works [8; 24].

\section{RESULTS}

It should be borne in mind that the responsibility for the development of students ' professional competencies, obtaining knowledge and skills necessary in professional and creative activities does not lie with one teacher.
The entire Department participates in the teaching process. Interaction of the teaching staff of the Department in order to create a productive, integrated pedagogical process will create an environment that will allow students to obtain high-quality professional knowledge and skills in the field of fine art and design. The course of lectures on aesthetics, history of culture and art and other disciplines of the professional module contribute to the development of practical disciplines $[18 ; 19]$.

Teachers in higher education need to pay special attention to the basics of the theory of academic drawing - the study of architectural and spatial construction, shaping, construction, compositional construction of the picture plane.

Teachers who teach professional subjects such as "Academic drawing" should focus on the lecture course. In-depth, highquality development of the theoretical foundations of visual literacy and the laws of proportional, constructive and perspective construction will allow you to transfer all the knowledge you have gained to practice $[6 ; 8 ; 9]$.

Paying equal attention to the study of the basics of the theory and practice of visual literacy, students consistently and gradually acquire knowledge when mastering certain tasks and exercises.

At the first stage, students need to form an image on a plane (A1 format), on which the composition should be reasoned. Students need to prove the correctness and conceptuality of their composition. Previously, the teacher tells the theoretical foundations and compositional features in the formation of the composition of the picture plane, the selected format, to identify all the features of building a linear and aerial perspective. It is necessary to theoretically justify the differences between the concepts of size and shape of objects and their proportions - the main principles of working from nature. Work from General to private. By formulating the basic principles of orientation in space, correct errors in the drawing.

It is necessary to adopt a method of comparative analysis of the original (model) and educational or creative drawing in the course of a practical task. You should also pay attention to the theory of shadows, the distribution of light on the surface of the form, based on the basic techniques and laws of the organization of the composition (line, spot).

In the process of organizing pedagogical activities aimed at developing aesthetic taste and compositional thinking, techniques of various forms of drawing, long and short-term drawing, as well as sketches are used. Analyzing the practical work, it can be noted that these forms should be separated, which differ in goals and objectives from each other.

The material under study should be mastered and consolidated by independent practical work under the guidance of a teacher.

Conscious study and understanding should be before the practical reproduction of skills, but without a large gap, to consolidate the theory in practice. The study of anatomical features and proportions of the human figure will allow you to reproduce them in practice most accurately, taking into account 
all the features and characteristics of the form. All forming parts are subordinated to a single whole. The whole includes all the details. Before the student starts drawing-constructive construction of the form, it is necessary to study its construction well [3; 25]. Analysis of the space, perspective, light, and shadow where the drawing object is located. The shape of the drawing object is considered as General to particular. The whole process of analyzing and understanding all the principles in the formation of an object on the plane must be learned consciously. This is based on the laws of working with the surrounding nature - from large to small or from General to particular.

The student must logically justify the compositional and constructive solution of their drawing, be able to explain all their actions in a graphic three-dimensional image. Using various forms of work in drawing, it is necessary to set students more creative tasks that develop compositional thinking. The basis for introducing drawing from memory and imagination into the educational process should be a deep study of the form in order to accurately convey its character.

Based on the laws of propaedeutics, practical work of students is carried out with the direct use of special literature, taking into account all aspects and features of each situation in the graphic image. There is another method that will not replace the theory, but can serve as an auxiliary one. This is "visual" trainingcopying the form. Without appropriate, necessary theoretical knowledge and skills to apply them in practice, students do not receive proper development, do not form as creative individuals, but only imitate and focus on the mechanical execution of the drawing $[14 ; 20]$.

The main task of the teacher's work is to Orient students to compositional and creative thinking. The educational process is aimed at teaching the future artist and designer to think creatively, analyze, reason and draw conclusions, depicting form and space.

Ignoring the principles of formation of the pedagogical process (lack of theoretical knowledge), students receive only visual information through their perception of the form and fix it, making a comparative analysis with the theory.

With the correct organization of the pedagogical process, which focuses not only on visual, but also on theoretical knowledge, the application of theory in practice, will further achieve the goal of developing compositional and creative thinking. This is the main thing in the process of training a future artist and designer.

Let's analyze examples of specific structural and anatomical forms:

1. Drawing of a human head. Students have a theoretical and practical task to study the anatomical and plastic content of the human head shape. To this end, before you start drawing, we study the basis of the human head (skull), structural and anatomical features of the head parts, ekorshe head (muscular system of the head), the proportions of the human head (canons). The formation of a drawing is based on the basic principles of drawing from nature ("from General to particular").

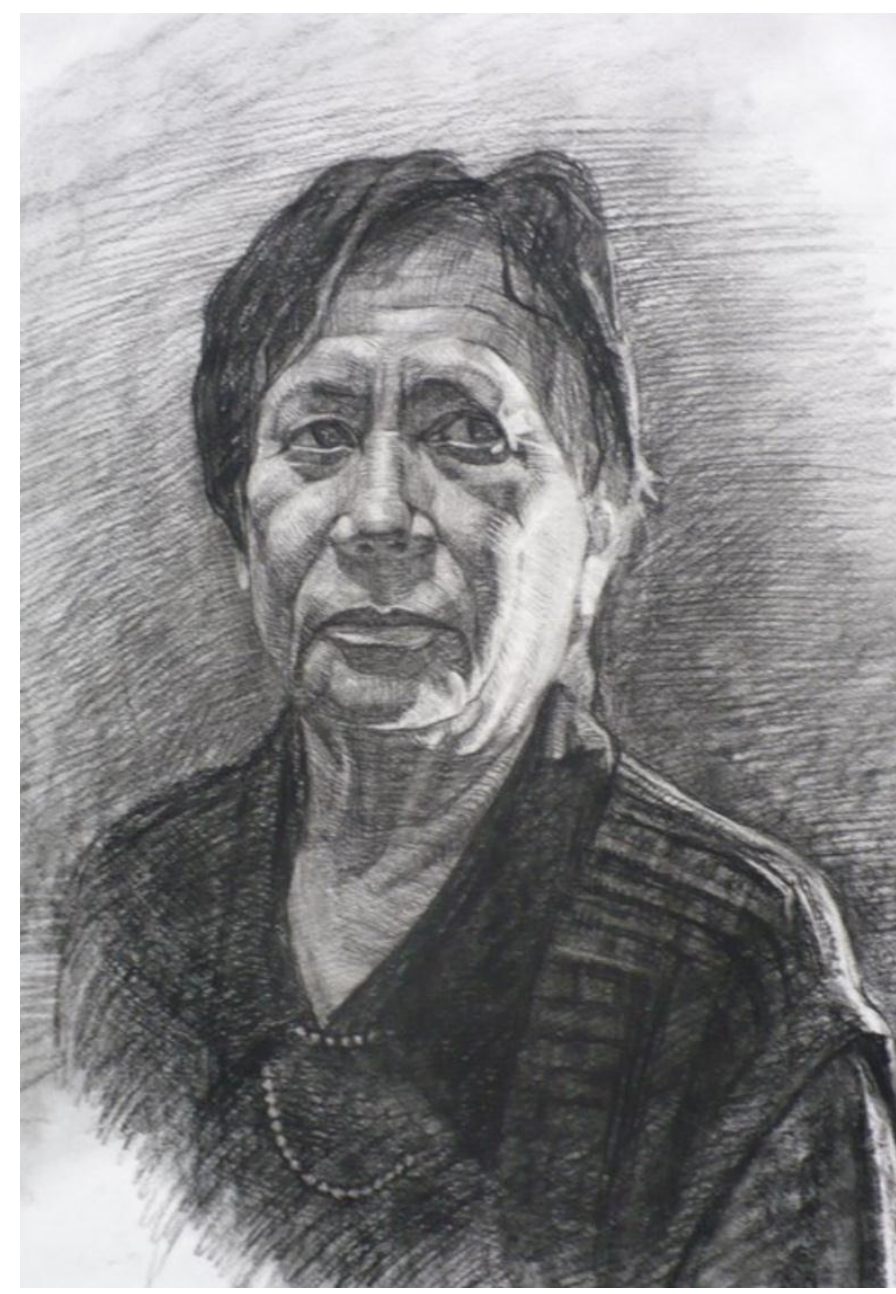

Figure 1. Drawing of the human head, student. Kostenko E., teacher Vasilenko P. G.

\section{Drawing of a human figure.}

Drawing a human figure requires knowledge of anatomical basics and proportions.

Students need to focus on simplifying the shape of the figure at the initial stage, gradually complicating it. Drawing a figure is based on the principle of drawing from nature - from General to particular and from large to small. Analyzing the shape, it is necessary to identify its plasticity.

The structural and technical organization of the form is gradually becoming more complex, and higher tasks are being set. The ability to manage the process of creating an image gradually filling it with information, distributing semantic and tonal accents and developing compositional load on the picture plane.

The teacher should Supplement the study of the theory of professional literature with practical clarifications and explanations. The main thing is to possess and be able to transfer professional practical and theoretical knowledge in 
drawing [7].

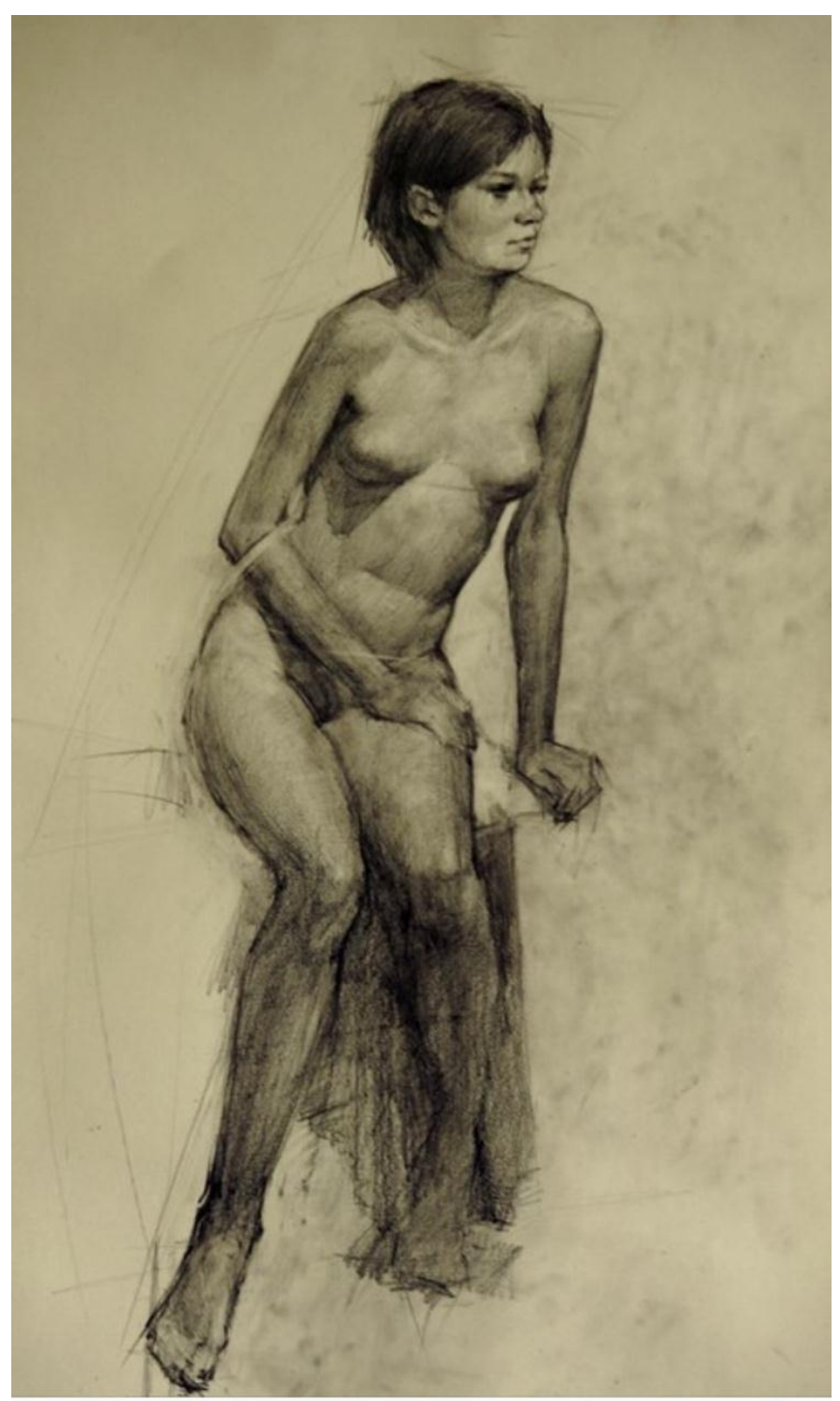

Figure 2. Figure of a human figure, student. Leushin D.. teacher Fursov A. I.

\section{Drawing of a clothed, Nude model (two-figure).}

When studying at the practical classes of the corresponding stage in the academic drawing, students analyze the plasticity and spatial perception of the form. In-depth study of various textures and materials, and textures.

Previously acquired knowledge, skills and abilities in simpler tasks on academic drawing from nature will be built almost independently using various methods that are used in this discipline.

Especially important during this period of training should be given to practice and creativity in solving educational problems. This will help form analytical and compositional thinking. The drawing should be with an individual approach, and not copying nature. The student analyzes, makes his conclusions and with his creative approach performs the task, creates an image $[5 ; 26]$.

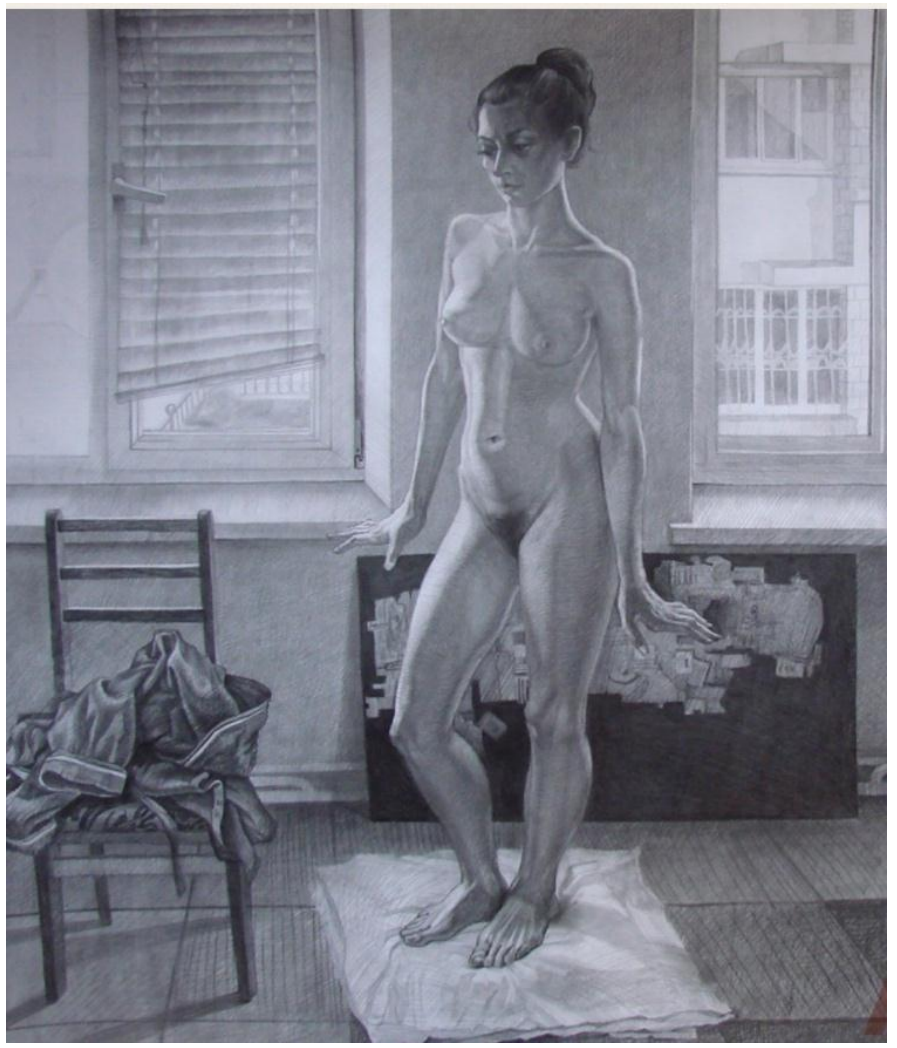

Figure 3. Model drawing-setting, Studio. Tarasova A., teacher Fursov A. I.

Modern professional and educational literature makes references to questions and problems in teaching, but without an in-depth theoretical approach with the condition of performing practical tasks, these are abstract statements. There is a need to find new methods and explanations of the theory for studying academic drawing at this important and complex stage, as creative and psychological tasks for creating an image are being solved.

\section{CONCLUSION}

One of the most important conditions for mastering The academic drawing program for students of higher professional education in the areas of Design and Fine art is an in-depth study of theory using practical classes. Introductory theoretical classes throughout the course of the educational process will have a positive impact on the development of the discipline and the acquisition of the required competencies.

Teachers do not pay enough attention 4to4 solving creative tasks in the educational process within the framework of contact (classroom) work. The development $\mathrm{o} 2 \mathrm{f} 2$ creative and creative thinking takes a back seat, the main attention is paid to the basics of visual literacy. In this regard, the propaedeutic course of drawing takes almost all the time of training. The teaching moment of professional art through drawing will lose its meaning. It is not always possible to create a sense of creative state on an academic drawing by following the path of imitating the external form of famous artists. Developing the 
creative abilities of the student, reducing everything to imitation and sensuality in isolation from thinking, forgetting the role and significance of creativity in the approach to academic drawing. It all comes down to the performance level - the level of imitative, not creating, not thinking.

Scientific approach and methodological developments, the creation of certain pedagogical conditions in the educational process of students in the direction of design and fine arts will increase the level of training of future professionals in this field. Innovative programs in academic drawing that will take into account the specifics of all areas and specialties in the visual arts are the most important aspects in the development of professional disciplines. We can conclude that it is necessary to make in-depth study of the theory and basics of visual literacy in the educational process for further application of the knowledge obtained in practical classes. The results obtained will help in the formation of an interdisciplinary synthesis that encourages students to creative activity.

\section{REFERENCES}

[1] Akim K, Kara-Murza G, Saenko N, Suharyanto A, Kalimullin D. Superhero movie: Breaking the challenges of topics in the modern epos. Opcion. 2019;35(Special Issue 22):1408-28.

[2] Beda GV. Fundamentals of visual literacy. Enlightenment, Moscow. 1989: P. 192.

[3] Beschastnov NP. Portrait graphics. Humanitarian publishing center VLADOS, Moscow. 2006: P. 368.

[4] Bochkareva TN, Akhmetshin EM. Zekiy AO, Moiseev AV, Belomestnova ME, Savelyeva IA, Aleynikova OS. The analysis of using active learning technology in institutions of secondary vocational education. International Journal of Instruction. 2020;13(3):371386. doi:10.29333/iji.2020.13326a

[5] Civardi G. Drawing. The human body: anatomy, morphology, plastic. Moscow: Eksmo. 2005: P. 112.

[6] Fatykhova A, Rakhmanina M, Vasilenko PG, Vasilenko EV, Gereev E. Development of corporate standard model of ict-competence of academic staff of a modern university. International Journal of Civil Engineering and Technology. 2018; 9(13):1027-1034.

[7] Fursov AI. Basic laws of perception of the form of objects in drawing still life from nature, in the collection of materials of the international scientific and practical conference in 2 parts, edited by: Gritsenko P., Alekseeva I.V., Zengina S.S., Enikeeva A.A. "Modernization of humanitarian art education: innovative development strategies". 2014:285-294.

[8] Fursov AI. On the modern understanding of the role of academic drawing in the educational process in higher school, in the collection of materials of the II festival of pedagogical skill "professional competence of a modern teacher". 2016:167-169.

[9] Gabidullina F, Galiullin R, Khakimova I, Mansurov I.
Elitist education: Historical experience of the russian and tatar peoples. Journal of Social Studies Education Research. 2020;11(1):267-280.

[10] Gladilina I, Yumashev AV, Avdeeva TI, Fatkullina AA, Gafiyatullina EA. Psychological and pedagogical aspects of increasing the educational process efficiency in a university for specialists in the field of physical education and sport. Espacios. 2018;39(21).

[11] Kashirskaya LV, Sitnov AA, Davlatzoda DA, Vorozheykina TM. Knowledge audit as a key tool for business research in the information society. Entrepreneurship and Sustainability Issues. 2020;7(3):2299-2319. doi:10.9770/jesi.2020.7.3(56)

[12] Kovalenko KE, Osadchy EA, Goloshchapova LV, Zekiy AO, Lvov VV, Meshkova GV, Bagautdinov AF. Models of business education in russia and their main competitive advantages. Journal of Entrepreneurship Education. 2019;22(3).

[13] Lopasova EV. Didactic principles of integral methodical system of development of compositional thinking of students, theory and practice of social development. 2012;10:137-139.

[14] Lushnikov BV, Pertsov VV. Drawing. Figurativeexpressive means. Humanitarian publishing center. VLADOS. 2006:P. 240.

[15] Nadtochy YV, Klochko EN, Danilina MV, Bazhenov RI, Bakharev VV. Economic factors and conditions for the transformation of the education services market in the context of globalization. International Review of Management and Marketing. 2016;6(1):33-39.

[16] Pallotta VI, Koltsova EA. Problems of design education in higher education. Krasnodar: Collection of scientific works: Multilevel system of art education and upbringing: Modern approaches in scientific research. 2013:P. 32.

[17] Pallotta VI, Sichkar TV. Semiotic design tools for organizing, selecting and using images in advertising. Costumology. Vol. 4. Moscow. 2019;4(2):P. 10.

[18] Prodanova NA, Savina NV, Dikikh VA, Enina YI, Voronkova OY, Nosov VV. Features of the coherent presentation of information in order to prepare integrated corporate reporting. Entrepreneurship and Sustainability Issues. 2020;7(3):2227-2281. doi:10.9770/jesi.2020.7.3(54)

[19] Rahman PA, Bobkova EY. The reliability model of the fault-tolerant border routing with two Internet services providers in the enterprise computer network. Journal of Physics: Conference Series. 2017;803(1). https://doi.org/10.1088/1742-6596/803/1/012124

[20] Radlov NE. Drawing from nature. Rostov on don: Artist of the RSFSR. 1978: P. 126.

[21] Roshchin SP. Formation of the personality of the artist and teacher in the process of professional training. MSPU Intercollegiate collection of scientific works. To 
International Journal of Engineering Research and Technology. ISSN 0974-3154, Volume 13, Number 11 (2020), pp. 3625-3630

(C) International Research Publication House. https://dx.doi.org/10.37624/IJERT/13.11.2020.3625-3630

the 15th anniversary of the state University of higher education and the 10th anniversary of the faculty of fine arts "Ways and means of improving the quality of art education and aesthetic education". Moscow.2010: 8-15.

[22] Samusenko AS, Plaskova NS, Prodanova NA. The Analysis of the External Environment to Determine the Practical Focus of Applied Research and Development in the Framework of Innovation. InComplex Systems: Innovation and Sustainability in the Digital Age 2020 (pp. 245-255). Springer, Cham.

[23] Saprykina VY, Lashko SI, Klochko EN, Yarushkina EA, Chumakova NA, Bugaenko VE. Organizationaladministrative Features of the Implementation of Educational Services in the Two-level System of Training of Highly Qualified Personnel. International Journal of Economics and Financial Issues. 2016;6(1S).

[24] Savina NN. The structure and content of the module" research and experimental activities of a teacher". The Social Sciences (Pakistan). 2015;10(7):1891-5.

[25] Sevostyanova ON, Smirnova MA. Development of students ' creative thinking in drawing architectural space. Space of urban civilization: ideas, problems, concepts. Urhajo. 2017:410-413.

[26] Vasilenko PG. The process of teaching academic drawing at art and graphic faculties. Krasnodar: Krasnodar state University of culture and arts. In the collection of materials of the regional scientific and practical conference "Kaygorodovskie readings". 2010:310-313.

[27] Vasilenko PG, Lopasova EV. Main directions of activity of the pedagogical worker on development of creative abilities of students of fine arts in the system of additional pre-professional education. Modernization of humanitarian and art education: innovative development strategies. 2014:104-110. 